$\underline{\text { REVIEW }}$

\title{
Pharmacological approach for drug repositioning against cardiorenal diseases
}

\author{
Yoshito Zamami ${ }^{1,2}$, Masaki Imanishi², Kenshi Takechi ${ }^{3}$, and Keisuke Ishizawa ${ }^{1,2}$ \\ ${ }^{1}$ Department of Clinical Pharmacology and Therapeutics, Institute of Biomedical Sciences, Tokushima University Graduate School, Tokushima, \\ Japan, ${ }^{2}$ Department of Pharmacy, Tokushima University Hospital, Tokushima, Japan, ${ }^{3}$ Clinical Trial Center for Developmental Therapeutics, \\ Tokushima University Hospital, Tokushima, Japan
}

\begin{abstract}
New applications of approved clinically used drugs are being discovered. Drug repositioning is a proposed strategy for developing these drugs as therapeutic agents for different diseases. Currently, approximately 2000 drugs are used in Japan. However, the compound targets and pathways involved in the pharmacological actions of 70-80\% of these drugs have not been adequately clarified. Pharmacological examination of approved drugs is an important task in drug repositioning and vital for improving drug development efficiency. This review reports that angiotensin II type 1 receptor blockers show receptor-independent effects against reactive oxygen species generation in renal cells. Additionally, nitrosonifedipine has an antioxidative effect and protects endothelial cells against oxidative stress, and pioglitazone has multiple effects that improve dysfunctions in vascular control regulated by adrenergic and calcitonin gene-related peptide-containing nerves in animal models of diabetes. These data suggest that some approved drugs could be useful for treating cardiorenal diseases. Since cardiorenal diseases are likely to have chronic pathological conditions and require chronic drug administration, highly safe drugs are needed. Compared to newly developed drugs, drug repositioning of approved drugs with safety information is considered a particularly useful technique for searching new treatments for cardiorenal diseases. J. Med. Invest. 64 : 197 -201, August, 2017
\end{abstract}

Keywords : Drug repositioning, pharmacology, cardiorenal diseases

\section{INTRODUCTION}

In recent years, new applications for approved drugs that are used clinically have been discovered. Therefore, drug repositioning has been proposed as a strategy for developing these drugs as therapeutic agents for different diseases (1). Approved drugs have already undergone clinical trials, and information on their safety and pharmacokinetics in humans is available. Therefore, in drug repositioning, it is possible to reduce the cost and shorten the duration of drug development while ensuring safety (1-3). Furthermore, since the pharmacokinetics of such drugs in humans have been clarified, gaps between animal studies and clinical trials are less likely to be found. Additionally, the success rates of developing such drugs are higher than those for new compounds.

Approximately 2000 drugs are currently reported to be used in Japan. However, $70-80 \%$ of these drugs have not been studied to determine their compound targets and mechanisms of action. Therefore, their pharmacological actions have not been adequately clarified. Pharmacological examination of approved drugs is an important task in drug repositioning. It is also an essential process that must be considered to improve the efficiency of drug development.

Cardiovascular disease (CVD) and chronic kidney disease (CKD, chronic renal disease) are closely related. The frequency of cardiovascular events was reported to increase with decreasing glomerular

Received for publication June 7, 2017 ; accepted August 22, 2017.

Address correspondence and reprint requests to Keisuke Ishizawa, Department of Clinical Pharmacology and Therapeutics, Institute of Biomedical Sciences, Tokushima University Graduate School, 3-18-15 kuramoto-cho, Tokushima, 770-8503 Japan and Fax : +81-88-633-7472. filtration rate (GFR) in a large resident health survey (4). In addition, background factors such as obesity, hypertension, diabetes, and dyslipidemia are known to reduce renal and cardiac functions. Furthermore, cardiovascular diseases are often chronic and frequently require medicines to be administered over a long period, and therefore, a high safety profile is required. However, there are no highly safe therapeutics for these cardiorenal diseases, which is a serious problem. In this review, we have summarized our data on pharmacological research aimed at repositioning drugs for the treatment of cardiorenal diseases (Fig 1).

Antioxidative effect of nifedipine photodegradation product in management of cardiorenal diseases

Nifedipine is a commonly used calcium channel blocker for treating hypertension; however, it is extremely light-sensitive. Nifedipine is converted to its nitroso analog nitrosonifedipine [2,6-dimethyl-4-(2-nitrosophenyl)-3,5-pyridinedicarboxylic acid dimethyl ester] (NO-NIF) (5-7) after photolysis. NO-NIF does not have a calcium channel blocking effect; however, it has a strong and unique radical scavenging ability. It reacts with lipid-derived radicals in vitro and participates in radical scavenging activities in the cell membrane (8). We focused on this unique radical scavenging activity and previously investigated the effects of NO-NIF in some oxidative-stress-related cardiorenal diseases using animal models (10-12).

First, the study investigated whether NO-NIF exhibits a higher 1,1-diphenyl-2-picrylhydrazyl (DPPH) radical scavenging activity than nifedipine does. Interestingly, a mixture of NO-NIF and unsaturated fatty acids exhibited an extremely stronger radical scavenging activity than NO-NIF alone did (8). Furthermore, an electron paramagnetic resonance (EPR) method revealed that 


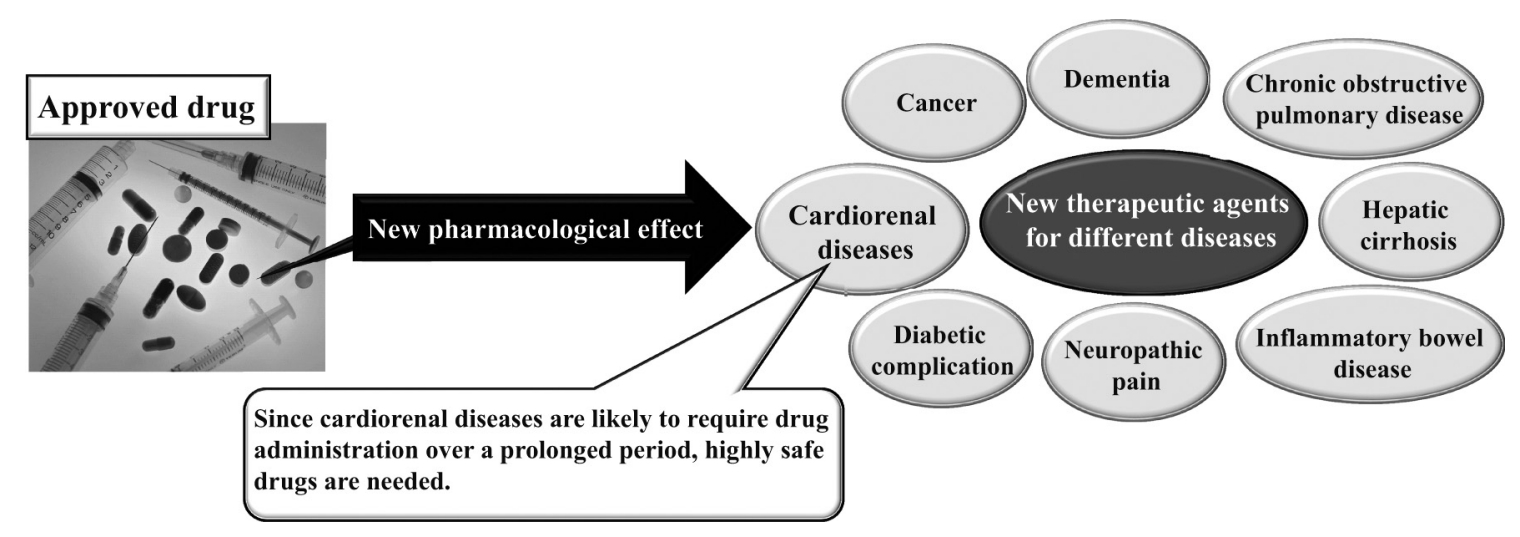

Fig. 1 Drug repositioning strategy using approved clinically used drugs

NO-NIF could be converted to its radical form through an in vitro reaction with unsaturated fatty acids, which are abundant in cell membranes, but not with saturated fatty acids. NO-NIF was also shown to be converted to its radical following a reaction with endothelial or vascular smooth muscle cells. EPR signals in the two cell types showed that the formation of NO-NIF radical continued for over 12 hours after the reaction stopped. In addition, characteristic aeolotropic triplet signals suggested that the radical stayed within the cell membrane. Thus, it was proposed that NO-NIF shows a unique strong radical scavenging activity that is prolonged by reacting with unsaturated fatty acids, after which it is converted to its radical form in the cell membrane (8).

NO-NIF has also been shown to suppress the decrease in cell viability caused by cumene-hydroperoxide-induced membrane peroxidation in endothelial cells (9). NO-NIF also suppresses the expression of intercellular adhesion molecule (ICAM) - 1 and the reduction in cell viability induced by tumor necrosis factor (TNF) $-\alpha$ in endothelial cells. Conversely, nifedipine does not similarly affect the decrease in cell viability. The results suggest that NO-NIF has a strong antioxidative effect and protects endothelial cells, which nifedipine does not exhibit.

Furthermore, the effects of NO-NIF have been investigated on the oxidative-stress-related pathogeneses of several cardiorenal diseases in mice. NO-NIF was shown to suppress protein urea excretion induced by $N^{\omega}$-nitro-L-arginine methyl ester (L-NAME), an inhibitor of nitric oxide synthase (NOS) (10). It also suppresses ICAM-1 expression in the rat aorta. However, a similar amount of nifedipine did not exhibit any of these effects. Moreover, because NO-NIF did not affect L-NAME-induced hypertension, the observed effects occurred independently of blood pressure (10).

The effects of NO-NIF on angiotensin II (Ang II) -induced vascular remodeling have also been investigated. The results showed that NO-NIF suppressed Ang-II-induced medial thickening by suppressing vascular smooth muscle cell proliferation, vascular fibrosis, and inflammation in the aortae of mice (11). In addition, it suppressed Ang-II-induced superoxide generation in the aorta and the urinary excretion of 8-hydroxydeoxyguanosine (8-OHdG) (11). Additionally, previous in vitro studies revealed that NO-NIF suppressed Ang-II-induced generation of reactive oxygen species (ROS), phosphorylations of epidermal growth factor receptor and AKT, and cell migration and proliferation (11). These results suggest that NO-NIF suppresses Ang-II-induced vascular remodeling via suppressing oxidative stress in the aorta. In addition, NO-NIF suppressed Ang-II-induced ICAM-1 expression in the aorta and Ang-II-induced blood pressure elevation. Thus, it was concluded that NO-NIF has a protective effect on endothelial cells. Because NO-NIF showed a strong antioxidative effect and protected endothelial cells, its effects were further investigated in a mouse model of diabetic nephropathy. Although NO-NIF did not affect glucose tolerance, it suppressed urinary protein excretion, glomerular expansion, ICAM-1 induction in the glomeruli, superoxide generation in the kidney, and urinary excretion of $8-\mathrm{OHdG}$ in KKAy mice with type 2 diabetes (12). Thus, NO-NIF alleviated type 2 diabetic nephropathy via its antioxidative effect without affecting glucose tolerance. These results suggest that NO-NIF may be a potential new therapeutic agent for managing cardiorenal diseases.

Receptor-independent effects of angiotensin II receptor blockers on renal cells

Ang II type 1 receptor (AT1R) blockers (ARBs) are major therapeutic agents for treating hypertension. However, several reports have indicated that the beneficial effects of ARBs on cardiorenal diseases are independent of blood pressure $(13,14)$. It has been suggested that ARBs have a renoprotective effect in addition to blood pressure-reducing effects (13-15). In addition, ARBs have unique properties such as anti-apoptotic, antioxidant, and antiinflammatory effects that are exerted in a receptor-independent manner (16-18).

Mesangial cell migration induced by platelet-derived growth factor (PDGF) has been shown to be inhibited by the ARB olmesartan (Olm) ; however, AT1R knockdown is not affected (19). Although results have shown that Olm does not exhibit a superoxide scavenging activity or affect the expression of PDGF receptors, it suppresses PDGF-induced ROS generation and its downstream phosphorylation pathway of Src and big mitogen-activated protein kinase 1 (BMK1), implicated in cell migration. Moreover, because Olm did not affect the hydrogen-peroxide-induced phosphorylation pathway, it is believed to affect PDGF-induced ROS generation but not its downstream phosphorylation pathway. Therefore, Olm has been proposed to suppress PDGF-induced ROS generation, leading to subsequent inhibition of Src/BMK1/migration in an AT1Rindependent manner.

Next, an active metabolite of Olm, RNH-6270, has been shown to suppress TNF- $\alpha$-induced cytotoxicity in glomerular endothelial cells (20). In addition, RNH-6270 suppressed cell death and the increase in ICAM-1 expression induced by TNF- $\alpha$ via inhibition of ROS in human glomerular endothelial cells.

In summary, these results showed that the receptor-independent effects of ARBs are implicated in ROS generation in renal cells. Additionally, those effects may be beneficial in the management of cardiorenal diseases. 
Ameliorating effect of pioglitazone in neurogenic vascular dysfunction in diabetes mellitus with insulin resistance

Pioglitazone is a thiazolidinedione derivative and a ligand for peroxisome proliferator-activated receptor- $\gamma(\operatorname{PPAR} \gamma)$. It is used in the treatment of diabetes mellitus with insulin resistance. Several studies have indicated that pioglitazone increases insulin sensitivity and inhibits the development of experimental hypertension (21-23). Therefore, active treatment with a PPAR $\gamma$ ligand is considered useful for treating insulin-resistant patients with complications such as hypertension and vascular disorders. Therefore, the ameliorating effects of pioglitazone on vascular control regulated by adrenergic and CGRPergic nerves have been investigated in diabetic rats.

First, acute insulin infusion has been demonstrated to augment adrenergic-nerve-mediated vasoconstriction and inhibit vasodilatation mediated by calcitonin gene-related peptide (CGRP) containing (CGRPergic) nerves in pithed rats without central vasoreflex $(24,25)$. Thus, insulin plays an important role in vascular control regulated by adrenergic and CGRPergic nerves.

Next, it has been demonstrated that rats administered 15\% fructose solution as their drinking fluid showed a marked increase in plasma insulin levels but not a significant increase in blood glucose levels. Moreover, fructose-drinking rats (FDR) with hyperinsulinemia showed signs of hypertension. Thus, hypertension appears to be closely associated with chronic hyperinsulinemia and insulin resistance. Furthermore, it has been indicated that fructosedrinking pithed rats with chronic hyperinsulinemia show augmented adrenergic-nerve-mediated vasoconstriction and decreased CGRPergic-nerve-mediated vasodilatation (26-29). Based on the reports, insulin likely exerts a neurogenic regulatory effect on vascular tone.

Finally, oral administration of pioglitazone to FDRs for 2 weeks markedly decreased their plasma levels of insulin, triglycerides, and glucose. However, untreated FDRs remained hypertensive, whereas the blood pressure of pioglitazone-treated FDRs markedly decreased to a level similar to that of the control rats (30). Furthermore, treatment of FDRs with pioglitazone has been shown to restore the activation of adrenergic nerves and blunt CGRPergicnerve-mediated vasodilator response ; however, exogenous CGRPinduced responses are not affected (30). Therefore, insulin resistance is associated with dysfunctions of vascular control regulated by adrenergic and CGRPergic nerves.

In conclusion, pioglitazone has been suggested to exert multiple effects that improve insulin resistance and neurogenic vascular dysfunction in a rat model of diabetes. In addition, pharmacotherapy using pioglitazone has been suggested to have the potential to effectively prevent the development of hypertension in patients who have diabetes mellitus with insulin resistance.

\section{CONCLUSION}

Recently, numerous drug repositionings have succeeded, and various drugs with novel efficacies against intractable diseases have been discovered (Table 1). In this review, we highlighted that ARBs show receptor-independent effects against ROS generation in renal cells, NO-NIF has an antioxidative effect and protects endothelial cells from oxidative stress in some animal models, and pioglitazone has multiple effects that improve dysfunctions in vascular control regulated by adrenergic and CGRPergic nerves in animal models of diabetes. These data suggested that some approved drugs could be useful therapeutic agents for treating cardiorenal diseases.

Cardiorenal diseases are often chronic pathological conditions that require drug administration over prolonged, and therefore, highly safe drugs are needed. Compared to newly developed drugs, drug repositioning of approved drugs with available safety information is considered a particularly useful technique for identifying new treatments for cardiorenal diseases. However, when an effective existing approved drug is out of patent, pharmaceutical companies are often reluctant to clinically apply because they cannot achieve profits. Therefore, drug repositioning should be promoted by researchers from countries and other sources.

Recently, a method of comprehensively analyzing the molecular effects of approved drugs using the latest analytical methods and examining their possibility as a therapeutic drug for other diseases is being carried out. In vitro systems such as high-throughput screening are used for efficacy discovery, and in silico systems based on drug and disease databases are often used for drug evaluation (3136). The development of the research highlighted in this review using these latest analytical methods would lead to the clinical application of many therapeutic agents in the management of cardiorenal diseases.

Table 1. New applications of approved drugs discovered by drug repositioning

\begin{tabular}{|c|c|c|c|}
\hline Drug & Approved applications & New applications & Year of report \\
\hline Acetophenazine & schizophrenia & Prostate cancer & 2007 \\
\hline Dutasteride & prostatauxe & Alzheimer & 2008 \\
\hline Tamoxifen & breastcancer & $\begin{array}{l}\text { systemic lupus } \\
\text { erythematosus }\end{array}$ & 2009 \\
\hline Ibudilast & asthma & neuropathic pain & 2010 \\
\hline Cimetidine & ulcer & lung cancer & 2011 \\
\hline Aspirin & anticoagulation & Prostate cancer & 2014 \\
\hline Ribavirin & antivirus & $\begin{array}{l}\text { Suppression of } \\
\text { cancer resistance }\end{array}$ & 2015 \\
\hline Carperitide & cardiac failure & $\begin{array}{l}\text { Metastasis of } \\
\text { lung cancer }\end{array}$ & 2015 \\
\hline Bezafibrate & hyperlipidemia & $\begin{array}{l}\text { Activation of } \\
\text { antitumor effect }\end{array}$ & 2017 \\
\hline
\end{tabular}

\section{ACKNOWLEDGEMENTS}

This study was supported by JSPS KAKENHI (15K07967).

\section{CONFLICT OF INTEREST}

The authors report no relationships that could be construed as a conflict of interest.

\section{REFERENCE}

1. Ashburn TT, Thor KB : Drug repositioning : identifying and developing new uses for existing drugs. Nat Rev Drug Discov $3: 673-683,2004$

2. Langedijk J, Mantel-Teeuwisse AK, Slijkerman DS, Schutjens $\mathrm{MH}$ : Drug repositioning and repurposing : terminology and definitions in literature. Drug Discov Today 20 : 1027-1034, 2015

3. Ferreira LG, Andricopulo $\mathrm{AD}: 33$. Drug repositioning approaches to parasitic diseases : a medicinal chemistry perspective. Drug Discov Today 21 : 1699-1710, 2016 
4. Go AS, Chertow GM, Fan D, McCulloch CE, Hsu CY : 33 . Chronic kidney disease and the risks of death, cardiovascular events, and hospitalization. N Engl J Med 351 : 1296-1305, 2004

5. Bauer V, Rekalov VV, Juranek I, Gergel D, Bohov P : Effect of illuminated nifedipine, a potent antioxidant, on intestinal and vascular smooth muscles. British journal of pharmacology $115: 871-874,1995$

6. Ohkubo T, Noro H, Sugawara K : High-performance liquid chromatographic determination of nifedipine and a trace photodegradation product in hospital prescriptions. Journal of pharmaceutical and biomedical analysis 10:67-70, 1992

7. Stasko A, Brezova V, BiskupicS, Ondrias K, Misik V : Reactive radical intermediates formed from illuminated nifedipine. Free radical biology \& medicine $17: 545-556,1994$

8. Horinouchi Y, Tsuchiya K, Taoka C, Tajima S, Kihira Y, Matsuda Y, Shishido K, Yoshida M, Hamano S, Kawazoe K, Ikeda Y, Ishizawa K, Tomita S, Tamaki T : Antioxidant effects of photodegradation product of nifedipine. Chem Pharm Bull (Tokyo) $59: 208-214,2011$

9. Fukuhara Y, Tsuchiya K, Horinouchi Y, Tajima S, Kihira Y, Hamano S, Kawazoe K, Ikeda Y, Ishizawa K, Tomita S, Tamaki $\mathrm{T}$ : Protective effect of photodegradation product of nifedipine against tumor necrosis factor alpha-induced oxidative stress in human glomerular endothelial cells. The journal of medical investigation : JMI 58 : 118-126, 2011

10. Ishizawa K, Yamaguchi K, Horinouchi Y, Fukuhara Y, Tajima S, Hamano S, Tomita S, Tsuchiya K, Tamaki T: Drug discovery for overcoming chronic kidney disease (CKD) : development of drugs on endothelial cell protection for overcoming CKD. Journal of pharmacological sciences 109 : 14-19, 2009

11. Sakurada T, Ishizawa K, Imanishi M, Izawa-Ishizawa $Y$, Fujii S, Tominaga E, Tsuneishi T, Horinouchi Y, Kihira Y, Ikeda Y, Tomita S, Aihara K, Minakuchi K, Tsuchiya K, Tamaki T: Nitrosonifedipine ameliorates angiotensin II-induced vascular remodeling via antioxidative effects. Naunyn-Schmiedeberg's archives of pharmacology $386: 29-39,2013$

12. Ishizawa K, Izawa-Ishizawa $\mathrm{Y}$, Yamano N, Urushihara M, Sakurada T, Imanishi M, Fujii S, Nuno A, Miyamoto L, Kihira Y, Ikeda Y, Kagami S, Kobori H, Tsuchiya K, Tamaki T : Nitrosonifedipine ameliorates the progression of type 2 diabetic nephropathy by exerting antioxidative effects. PLoS One 9 : e 86335, 2014

13. Viberti G, Wheeldon NM : Microalbuminuria reduction with valsartan in patients with type 2 diabetes mellitus : a blood pressure-independent effect. Circulation $106: 672-678,2002$

14. Parving HH, Lehnert H, Brochner-Mortensen J, Gomis R, Andersen S, Arner P: The effect of irbesartan on the development of diabetic nephropathy in patients with type 2 diabetes. N Engl J Med 345 : 870-878, 2001

15. Ogawa S, Mori T, Nako K, Kato T, Takeuchi K, Ito S : Angiotensin II type 1 receptor blockers reduce urinary oxidative stress markers in hypertensive diabetic nephropathy. Hypertension 47 : 699-705, 2006

16. Akishita M, Nagai K, Xi H, Yu W, Sudoh N, Watanabe T, Ohara-Imaizumi M, Nagamatsu S, Kozaki K, Horiuchi M, Toba K : Renin-angiotensin system modulates oxidative stressinduced endothelial cell apoptosis in rats. Hypertension 45 : 1188-1193, 2005

17. Shao J, Nangaku M, Inagi R, Kato H, Miyata T, Matsusaka T, Noiri E, Fujita $\mathrm{T}$ : Receptor-independent intracellular radical scavenging activity of an angiotensin II receptor blocker. J Hypertens 25 : 1643-1649, 2007

18. Cianchetti S, Del Fiorentino A, Colognato R, Di Stefano R, Franzoni F, Pedrinelli R: Anti-inflammatory and anti-oxidant properties of telmisartan in cultured human umbilical vein endothelial cells. Atherosclerosis $198: 22-28,2008$

19. Ishizawa K, Izawa-Ishizawa Y, Dorjsuren N, Miki E, Kihira Y, Ikeda Y, Hamano S, Kawazoe K, Minakuchi K, Tomita S, Tsuchiya K, Tamaki T : Angiotensin II receptor blocker attenuates PDGF-induced mesangial cell migration in a receptorindependent manner. Nephrol Dial Transplant 25 : 364-372, 2010

20. Izawa-Ishizawa $Y$, Ishizawa K, Sakurada T, Imanishi M, Miyamoto L, Fujii S, Taira H, Kihira Y, Ikeda Y, Hamano S, Tomita S, Tsuchiya K, Tamaki T : Angiotensin II receptor blocker improves tumor necrosis factor-alpha-induced cytotoxicity via antioxidative effect in human glomerular endothelial cells. Pharmacology $90: 324-331,2012$

21. Zhang HY, Reddy SR, Kotchen TA : Antihypertensive effect of pioglitazone is not invariably associated with increased insulin sensitivity. Hypertension $24: 106-110,1994$

22. Buchanan TA, Meehan WP, Jeng YY, Yang D, Chan TM, Nadler JL, Scott S, Rude RK, Hsueh WA : Blood pressure lowering by pioglitazone. Evidence for a direct vascular effect. J Clin Invest $96: 354-360,1995$

23. Grinsell JW, Lardinois CK, Swislocki A, Gonzalez R, Sare JS, Michaels JR, Starich GH : Pioglitazone attenuates basal and postprandial insulin concentrations and blood pressure in the spontaneously hypertensive rat. Am J Hypertens 13 : 370-375, 2000

24. Takatori S, Mizote M, Zamami Y, Kurosaki Y, Kawasaki H : Effects of insulin on vascular responses to spinal cord stimulation and vasoactive agents in pithed rats. $\mathrm{Br} \mathrm{J}$ Pharmacol 140 : 1137-1145, 2003

25. Zamami Y, Takatori S, Yamawaki K, Miyashita S, Mio M, Kitamura Y, Kawasaki H : Acute hyperglycemia and hyperinsulinemia enhance adrenergic vasoconstriction and decrease calcitonin gene-related peptide-containing nerve-mediated vasodilation in pithed rats. Hypertens Res 31 : 1033-1044, 2008

26. Takatori S, Zamami Y, Mio M, Kurosaki Y, Kawasaki H : Chronic hyperinsulinemia enhances adrenergic vasoconstriction and decreases calcitonin gene-related peptide-containing nerve-mediated vasodilation in pithed rats. $\mathrm{P}$ Hypertens Res $29: 361-368,2006$

27. Zamami Y, Takatori S, Goda M, Koyama T, Iwatani Y, Jin X, Takai-Doi S, Kawasaki H : Royal jelly ameliorates insulin resistance in fructose-drinking rats. Biol Pharm Bull 31 : 21032107, 2008

28. Zamami Y, Takatori S, Hobara N, Yabumae N, Tangsucharit P, Jin X, Hashikawa N, Kitamura Y, Sasaki K, Kawasaki H : Hyperinsulinemia induces hypertension associated with neurogenic vascular dysfunction resulting from abnormal perivascular innervations in rat mesenteric resistance arteries. Hypertens Res 34 : 1190-1196, 2011

29. Takatori S, Zamami Y, Hashikawa-Hobara N, Kawasaki H : Insulin resistance-induced hypertension and a role of perivascular CGRPergic nerves. Curr Protein Pept Sci 14 : 275-281, 2013

30. Takatori S, Zamami Y, Yabumae N, Hanafusa N, Mio M, Egawa T, Kawasaki H : Pioglitazone opposes neurogenic vascular dysfunction associated with chronic hyperinsulinaemia. Br J Pharmacol 153 : 1388-1398, 2008

31. Dudley JT, Sirota M, Shenoy M, Pai RK, Roedder S, Chiang AP, Morgan AA, Sarwal MM, Pasricha PJ, Butte AJ : Computational repositioning of the anticonvulsant topiramate for inflammatory bowel disease. Sci Transl Med 3 : 96ra76, 2011

32. Zhao S, Nishimura T, Chen Y, Azeloglu EU, Gottesman O, Giannarelli C, Zafar MU, Benard L, Badimon JJ, Hajjar RJ, Goldfarb J, Iyengar R: Systems pharmacology of adverse event mitigation by drug combinations. Sci Transl Med 5 : 
206ra140, 2013

33. Gibson CC, Zhu W, Davis CT, Bowman-Kirigin JA, Chan AC, Ling J, Walker AE, Goitre L, Delle Monache S, Retta SF, Shiu YT, Grossmann AH, Thomas KR, Donato AJ, Lesniewski LA, Whitehead KJ, Li DY : Strategy for identifying repurposed drugs for the treatment of cerebral cavernous malformation. Circulation $131: 289-299,2015$

34. Ghosh CC, Thamm K, Berghelli AV, Schrimpf C, Maski MR, Abid T, Milam KE, Rajakumar A, Santel A, Kielstein JT, Ahmed A, Thickett D, Wang K, Chase M, Donnino MW, Aird WC, Haller H, David S, Parikh SM : Drug Repurposing Screen Identifies Foxo1-Dependent Angiopoietin-2 Regulation in
Sepsis. Crit Care Med 43 : e230-40, 2015

35. Wang K, Wan M, Wang RS, Weng Z : Opportunities for Webbased Drug Repositioning : Searching for Potential Antihypertensive Agents with Hypotension Adverse Events. J Med Internet Res 18 : e76, 2016

36. Naoya Hashikawa, Yuta Utaka, Takumi Ogawa, Ryo Tanoue, Yuna Morita, Sayumi Yamamoto, Satoru Yamaguchi, Masafumi Kayano, Yoshito Zamami, Narumi Hashikawa-Hobara : HSP 105 prevents depression-like behavior by increasing hippocampal brain-derived neurotrophic factor levels in mice. Sci Adv 3 : e1603014, 2017 